\title{
Exploring Hotel Policies about Cancellation's Penalties
}

\author{
Chieh-Heng Ko \\ Department of Hospitality Management, College of Tourism and Hospitality, Da-Yeh University, Taiwan \\ Email: chko@mail.dyu.edu.tw
}

How to cite this paper: Ko, C.-H. (2022) Exploring Hotel Policies about Cancellation's Penalties. Open Access Library Journal, 9: e8427.

https://doi.org/10.4236/oalib.1108427

Received: February 6, 2022

Accepted: February 22, 2022

Published: February 25, 2022

Copyright (C) 2022 by author(s) and Open Access Library Inc.

This work is licensed under the Creative Commons Attribution International License (CC BY 4.0).

http://creativecommons.org/licenses/by/4.0/

\section{(c) (i) Open Access}

\begin{abstract}
This study deals with the related issues and problems of hotel reservations, cancellations, no shows, holdovers, early departures, overbooking, oversales, upgrades, walks, and the associated non-performance penalties or compensation. Specifically, we concentrate on non-performance penalties related to late cancellations and no shows, early departures, and walks. Because of the growing importance of the meetings, incentives, conventions, and exhibitions market, special attention is paid to group reservations, group sales contracts, and attrition clauses which penalize meeting planners for not picking up the agreed upon number of blocked room nights. Comparisons are then made with the cruise, airline, and car rental industries. Comparative statistics show that overall, hotels have outperformed the airlines and car rental agencies, but not the cruise lines. We conclude with recommendations for greater efficiencies in managing non-performance penalties or compensation for the hotel industry.
\end{abstract}

\section{Subject Areas}

Tourism Economy

\section{Keywords}

Hotel Reservations, Cancellations, No Shows, Early Departures, Attrition, Walks, Non-Performance Penalties

\section{Introduction}

Hotels quote all kinds of rates, but two that are seldom mentioned are the overbooking and "sorry we are out of rooms" rates. Here's the problem. Guests book rooms and then fail to cancel in a timely way, or simply do not show up. No shows deprive hotels of potential revenues generated from perishable assets, and 
therefore cause them to overbook, sometimes leading to oversales. And if upgrades are exhausted, oversales lead to walks. The problem of cancellation/no shows, overbooking, and walks is therefore a triumvirate of inter-related issues. This paper deals with non-performance penalties, which involve late cancellations and no shows, early departures, oversales leading to walks, and group attrition when the number of room nights actually used and paid for falls short of that blocked off for a group.

In an early article, Gould et al. [1] reported that in most commercial markets, the hotel no-show rate for expected arrivals was anywhere from $5 \%$ to $15 \%$. The problem today is much less, because almost all hotels now insist that room reservations must be guaranteed with credit cards, and if hotel guests do not cancel their reservations in a timely way, they are usually charged the equivalent of one night's stay, plus taxes [2]. Thus, according to our survey of hotels, the no-show rate today has fallen to around $5 \%$, lowering the necessary overbooking rate, and concomitantly reducing the incidence of upgrades and walks due to oversales. The no-show rate for hotels is low compared to the airline industry, which airline economists we contacted tell us is around $8 \%$. The no-show rate for the hotels is also much lower than in the rental car industry, which is about $20 \%-25 \%$ [3], and which may be as high as $70 \%$ in Taiwan, because nation-wide, reservations are not normally guaranteed by credit cards, unless it is for special vehicles such as minivans, luxury cars, four-wheel drives, and convertibles, or during high-demand periods in prime locations. But the no-show rate of less than $1 \%$ (from a separate survey of six cruise executives) is much lower in the cruise industry, which requires full payment, usually 2 months or more before the departure date.

While hotels are compensated for one night's stay in the case of no shows, because almost all reservations are guaranteed, hotels still need to protect themselves against late cancellations and unexpected departures, and potential loss of down-line revenues in the case of multiple night reservations. Note that a hotel room is a perishable asset in that if it is left empty, unlike a tangible asset, it cannot be resold later. Thus revenues once lost cannot be recovered. Also, in a typical hotel, the high overheads and most of the expenditures are independent of the level of room utilization [4], and given low variable costs and perishable assets, it is important that once prices have been set, all rooms should be sold. As we will see below, the problem of perishable asset revenue management (PARM) has been widely investigated, both for the airlines as well as the hotel industry.

\section{Literature}

In the area of PARM, Ladany [4] claimed that over 100 technical PARM-related papers have been published, none of which purport to address all aspects of the topic. In fact, in a celebrated article, Weatherford and Bodily (1992) [5] came up with a comprehensive taxonomy of 14 elements (such as capacity) and their accompanying descriptors (example, fixed or variable). They calculated that there are an astounding 124,416 possible combinations of elements and descriptors. 
The earliest article on hotel overbooking was by Rothstein [6], in which he proposed a Markovian sequential decision model, showing how hotels can adjust overbooking limits at various decision points leading up to a target date, while recognizing the stochastic nature of reservations, cancellations, and no-show rates. The latest article was by Toh and DeKay [2], which according to the Weatherford and Bodily taxonomy, examined the problem of random correlated individual demand, uncertain cancellations and no shows leading to overbooking, and oversales of multiple grades of a discrete perishable asset of fixed capacity. They also allowed for the possibility of upgrades as well as non-auction displacement procedures, and proposed continuous-time dynamic decision rules. Furthermore, they dealt with multiple night reservations, and the concomitant problem of early departures and holdovers. Those who are interested in reviewing the literature on overbooking in the service industry are directed to Bitran and Mondschein [7], Hadjinicola and Payani [8], Badinelli [9], and Toh and DeKay [2], all of which provide up-to-date and very comprehensive reviews of the research on this topic. They serve as backdrops for our discussion of the related problems of no shows, cancellations, early departures, attrition, holdovers, overbooking, oversales, upgrades, and walks, and how these impact on nonperformance penalties and compensation.

The rest of the paper is organized as follows. We will discuss our questionnaires and survey results with respect to no shows, early departures, holdovers, overbooking, and walks, first with respect to individual reservations, and then to groups. Specifically, we will deal with the issue of non-performance penalties and compensation. We note that in the last decade or so, the meetings, incentives, conventions, and exhibitions (MICE) market has become very important, making group block bookings the most important source of revenues for many large convention hotels. Attendant to the growth of this market, attrition clauses penalizing groups for falling short of room blocks have become very popular in recent years. A large portion of the section on survey results will be devoted to group reservations and their associated issues and problems. We will then compare and contrast key statistics and practices in the hotel, cruise, airline, and car rental industries. Finally, we will conclude by advancing several recommendations for the hotel industry.

\section{The Sample}

The information reported below was collected from 20 hotels during several rounds of personal and telephone interviews and mail questionnaires over a 1-year period in 2021-2022. This is the sequence of what we did. After going through the literature, we were able to construct a comprehensive survey instrument consisting of 44 questions. We then contacted several hotels in a large metropolitan area considered a convention city, and managed to get six hotels to agree to participate (some declined because of confidentiality concerns). The questionnaires were sent to what we will generically call room managers (titles differed, but they were all performing the same task), so they could look up the 
answers. About 2 - 4 weeks later, we separately interviewed six room managers in their premises for approximately $90 \mathrm{~min}$. After determining the institutional structure of the industry through these intense personal interviews, we later interviewed another six hotels by telephone, to enlarge the sample size on $20 \mathrm{cru}$ cial statistics such as the no-show and early departure rate, and the percentage of holdovers. Upon tabulating all the results, we had to recontact several of the respondents who had supplied answers that appeared to be abnormally large or small. Upon clarification, they revised their answers, because they had misinterpreted the questions. All of the above was done pursuant to a previous study on hotel overbooking [2].

When we embarked on this study of non-performance penalties, based on what we learned from our previous surveys and the literature review, we constructed another 37-item questionnaire (more targeted toward the present study) divided into four categories: hotel characteristics, occupancy statistics, reservation policies, and group bookings. Advance copies of our new questionnaire were sent to eight different hotels in the same metropolitan area. After a reasonable period allowing the questionnaires to be read, we personally interviewed four of the room managers in their premises for more than 1 hour each, and interviewed one of them by telephone. Three of the eight hotels mailed back their completed questionnaires. Thus with the previous 12 surveys, we have a total sample of 20 hotels, 10 personally interviewed, seven interviewed by phone, and three surveyed by mail questionnaire. Because of the sensitive nature of the answers (for example, the overbooking rate and walking protocol), all of them requested strict confidentiality, especially when they provided us with documents (containing proprietary language) constructed by their corporate lawyers. To honor this request, we have reported our results in such a way that none of them can be identified.

Given our quota sample of 20 hotels, 11 of them were small with around 200 rooms, seven were medium-sized with between 300 and 600 rooms, and two were large with more than 800 rooms. In the context of overbooking, all of them basically had two types of rooms: luxury/deluxe and handicapped rooms, which are protected in that they are never or seldom oversold (particularly the latter), and standard rooms, which can be and are oversold. The proportion of protected rooms to the total number of rooms varies somewhat, but averages around $19 \%$.

The small hotels cater mainly to individuals (business as well as pleasure travelers), while the large establishments cater largely to conventions, meetings, and regular groups such as travel groups and airline crews, with more than $60 \%$ of their rooms dedicated to group reservations. The medium-sized hotels cater to both individuals and groups.

Annual occupancies were within a range $57 \%-83 \%$, and averaged $71 \%$ for all 20 hotels, above the national average of $59 \%$ for 2020 , partly because all our hotels are located in a convention city. All the hotels reported that their peak period is in the summer and fall months between June and October, with the latter the busiest month for conventions. Monday-Thursday are the busiest days. The 
number of days when all the rooms were occupied averaged around 46 days per year. This establishes an important observation that an average annual occupancy of $71 \%$ for the 20 hotels does not preclude the need for overbooking during those 46 peak days to protect against cancellations, no shows, and unexpected departures.

\section{Individual Bookings}

Individual reservations tend to rise as the arrival day approaches, and peak between 3 and 10 days out; many of the hotels report that the peak period for individual reservations is shortening. Unlike in the past, according to the hotels we interviewed, today almost all hotels will accept a reservation only if it is guaranteed by a credit card or a deposit equal to the first night's room rate plus taxes, unless a guest calls in from the airport with an intention of arriving shortly, in which case the room is guaranteed up to $6: 00$ p.m. of the same day. For the 20 hotels we surveyed, the deadline for late cancellations varies from 6:00p.m. of the day of arrival to 24 hour's notice. But De Lollis [10] notes that resort hotels and those located in popular convention cities often require 72 hours notice, and rooms booked through the Internet at heavy discounts will be charged for the first night's stay, or sometimes for the entire duration of the stay, even if notice is given more than 72 hours before arrival.

However, the most common practice is that cancellations must be made at least 24 hours before 6:00 p.m. of the day of arrival, otherwise the guest's credit card will be billed for the agreed price of the first night's stay, including taxes. Thus the hotels interviewed reported relatively low no-show rates averaging $5.4 \%$. Our survey reveals that business travelers have higher no-show rates than pleasure travelers, probably because the benefit of changing travel plans at the last moment due to altered business commitments exceeds the cost of the penalty, or perhaps because they do not personally end up paying the no-show penalty, and therefore do not bother to cancel the reservations in a timely way. From our survey, airport hotels, which serve mainly business people, appear to have higher no-show rates.

There appears to be a wide range in the percentage of multiple night reservations, depending on the nature of the clientele (business travelers tend to stay for only one night unless they are attending a convention or meeting), but on average, $61 \%$ of all reservations are for multiple nights, and the average length of stay is slightly more than two. Some of the hotels (in particular, those belonging to the bigger chains) have started to assess penalties of between US $\$ 30$ and US\$75 for early departures, resulting in a low average unexpected departure rate of 5.3\%. One hotel room manager reported that she managed to bring down the early departure rate from $11 \%$ to $3.5 \%$ by assessing a US $\$ 75$ penalty. Complementarily, when some guests do not leave on schedule, they become unexpected stayovers or holdovers (in our survey, an average of $6 \%$ of the stayovers holdover, meaning they do not leave on the day expected, and may contribute to oversales). In some places, holdovers can be considered as trespassers, and can be 
evicted, but in most places, holdovers have first priority over the rooms in that they have "squatter's rights" [2]. Walk-ins are people who arrive without reservations, and are treated as low-priority standbys to be accommodated only on a room available basis. Yesawich [11] claimed that they constituted 15\% of a hotel's business. However, our survey shows that the walk-in rate is very low (averaging seven rooms per hotel), probably because most of our hotels are located near city centers, and cater mainly to business clients rather than individuals or families driving by. Also, unlike motels and resorts, hotels do not have vacancy signs for drive by traffic. The existence of a substantial walk-in market would compensate for no shows and unexpected departures, and would make overbooking less compelling. Because our surveys show that walk-ins constitute an insignificant portion of the market for our metropolitan hotels, they cannot be relied upon to compensate for no shows and early departures, thus overbooking is more compelling among hotels than among motels and resorts which have a buffer by way of walk-ins.

Overbooking practices and policies tend to vary by the size of the hotel. The small hotels rely on the experience of the room manager to adjust reservation levels during peak periods according to historical records and personal expertise. The large hotels rely on sophisticated computer programs that use artificial intelligence to scan historical data and track patterns, resetting overbooking levels every $15 \mathrm{~min}$ or so, based on their global reservation systems. The medium-sized hotels tend to use a combination of proprietary computer programs, and the judgment of the room managers.

In fact, there are no statutory or administrative laws prohibiting hotel overbooking. Thus like the airlines, hotels start out by overbooking aggressively many months out to compensate for unreliable or speculative early bookings, and then tighten up their reservation levels as the day of arrival approaches [2]. Authorized overbooking levels can be over-ridden by the room manager for special reasons. For example, if a family requests several rooms for a multiple night stay, hotels will do a revenue displacement analysis to compute the opportunity cost of denying the reservation and the cost of walking clients with guaranteed reservations on some nights. For a full discussion of the importance of length of stay considerations, see Weatherford [12]. Also, our survey respondents admit that overbooking levels are usually increased to accommodate regular VIPs whose reservations will then be protected. What if overbooking leads to oversales and walks? Our research reveals that when overbooking leads to oversales, hotels will first try to upgrade their oversold guests to the luxury rooms (and sometimes even the handicapped rooms are sold). But when walks are inevitable (our hotels averaged 10 nights per year when walks occurred) hotel policies appear to be somewhat uniform. First, VIPs on comps, regular airline groups, those belonging to frequent-stayer programs, families on multiple night stays, conventioneers, and unaccompanied minors and single women are often protected. Guests with single night reservations and families on leisure travel are especially targeted for walks, and then the last oversold guests arriving are walked on a first- 
come-first-served basis. Sometimes by afternoon, if the number of unexpected stayovers and arrivals is larger than anticipated, some hotels will try to get volunteers with signs, or by asking them when they arrive. One of the hotels we interviewed offered US $\$ 50$ in displacement compensation as an inducement to walk, but no free room. Most guests on corporate expense accounts prefer to take the cash.

As we have previously noted, there are no federal laws governing compensation for walks, thus contract law governs compensation in the hotel industry [13]. But as a practical matter, our research reveals that walked guests are typically provided free nights in comparable hotels, plus transportation, and one free long distance call, until rooms are available at the original hotel, where they will usually receive a courtesy upgrade. When anticipating walks, hotels will pre-purchase rooms in comparable nearby hotels, preferably within their chains, or management groups at considerable discounts (around 33\%, according to our surveys). The number of walks is governed by the equation: Stayovers + holdovers - early departures + expected arrivals - no shows + walk-ins - upgrades $=$ rooms occupied + walks. Note that walks can also occur when there is an unexpected maintenance problem with rooms that have been booked.

\section{Group Bookings}

Since all the hotels we interviewed are located in a convention city, we asked several related questions on group bookings. Group reservations are generally considered to consist of 10 rooms or more, and can be associated with conventions, business meetings, the travel industry such as with airline crews and tour groups, or private functions such as reunions and weddings, but according to our survey respondents, the MICE market is the largest. Among the 20 metropolitan hotels we surveyed, the percentage of rooms filled by groups averages $42 \%$.

There are two sources of convention-related group bookings: indirect requests from professional meeting planners, and direct requests from corporate, professional, and academic groups. The process of negotiation starts with a Request For Proposal. After qualifying the account by successfully matching rooms requested with rooms available, the hotel's group sales office will respond with a formal proposal of rooms and facilities available, and room rates and catering charges, etc., in a competitive bid. (Note that almost no hotel will sell all of its available rooms, because hotels do not want to disappoint their regular customers, such as airlines and tour agencies, and business travelers.) If the proposal is accepted, then both sides will sign a group sales agreement, almost certainly with attrition clauses, which we were told became popular in the 1990s [14], and which spell out penalties for unfilled blocks, cancellations, and no shows. Note that some government agencies are prohibited from agreeing to attrition clauses. We found that meeting planners often refuse to accept attrition clauses imposed by overflow hotels (smaller hotels that are invited to accept reservations that the large convention hotels cannot accommodate because of space limitations). 
We were told that officers of the organization will usually be given complimentary suites or upgrades (the number usually depending on the number of rooms occupied by the group) so they can have small meetings in their rooms, but the rest of the group will usually get standard rooms at a group discount (up to $40 \%$ from the rack rate, but the average is about $20 \%$ ), partly to discourage group members from booking around the convention to get lower rates. Usually, conventions are booked a year or two in advance, but there have been instances when they have been booked

10 years out by professional organizations (such as the Taiwan Medical Association), which rotate the locations of their annual conventions. Group sales agreements usually allow for penalty-free percentage reductions in the number of booked rooms over time, for example, 6 months out, 3 months later, and then 30 days before the date of arrival. After that, the group is responsible for any shortcoming in the room block less the permissible reductions over time, by way of agreed upon liquidated damages. Thus hotels are protected against unfilled blocks, cancellations, no shows, as well as early departures. According to our surveys, normally the liquidated damages are for $70 \%-90 \%$ of the lost room revenues, plus applicable taxes, and sometimes they are on a sliding scale, based on show-up performance. Group discounts for catered events may be withdrawn if a certain percentage of conventioneers do not show up. Sometimes, the convention is made responsible for shortcomings in the minimum agreed catered food and beverage revenue. Stiff cancellation fees on a time-related sliding scale are imposed if the entire event is cancelled, with higher penalties closer to the event date [15], with usual exceptions for force majeure, such as war, riots and strikes, etc. Attrition clauses are necessary, because whenever a group sale contract is signed, the hotel relies on the anticipated revenue to cover set up costs, facility improvements, and sales commissions (for instance to the convention bureau). Hotels also must protect themselves against blocking rooms that are subsequently unfilled, depriving them of potential room revenue.

Savvy professional meeting planners usually insist that hotels do not sell into group bookings until after the group cut-off date, because all room nights are guaranteed. Thus, overbooking is discouraged upon special penalties for walks. They also insist on "resale protection" [16] in that if the hotel manages to sell the unfilled rooms, the revenues saved will be credited against the penalties (thus no double dipping). We learned that hotels protect themselves by insisting that credits be given on the basis of the "last sale rule." For example, if the hotel has a capacity of 2000 room nights during the duration of the convention, and a group commits to 1000 room nights while only 900 materialize, then the group is responsible for 100 room nights. The hotel sells its other empty rooms and credits the group only if fewer than 100 room nights are left empty. Early departure penalties are usually credited back to the convention as a credit against attrition penalties.

The room managers tell us that attrition clauses are seldom invoked, because professional and corporate meeting planners are very experienced, but they are 
enforced when violated [17]. Moreover, much to the credit of the hospitality industry, hotels exchange historical profiles of past conventions to allow hotels to adjust booking levels by selling into group bookings to avoid invoking attrition clauses. To maintain goodwill, sometimes hotels will waive the attrition penalties in return for future conventions booked during off-peak periods. Or they will accept a portion of the agreed upon penalties to avoid going into litigation. In the case of unanticipated or unavoidable events, attrition contracts are not enforced. In talking to the room managers, we got the distinct impression that they regard enforcing attrition clauses as a very unpleasant task. Thus, hotels encourage meeting planners to inform them of anticipated short-comings, so that they can sell into the group bookings, and thus reduce the impending penalties.

\section{Comparisons with Cruise Lines, Airlines}

The related problems of cancellations, no shows, early departures, holdovers, overbooking, oversales, upgrades, walks, and non-performance penalties/compensation are common to all sectors of the hospitality industry that accept reservations. We now compare and contrast hotels with cruise lines, airlines in Table 1. Data are from past and present research and work experience on various sectors of the travel industry, and from our literature search.

Table 1. Comparison among hotels, cruise lines, airlines, and car-rental companies.

\begin{tabular}{|c|c|c|c|c|}
\hline & Hotels & Cruise lines & Airlines & Car rentals \\
\hline $\begin{array}{l}\text { Multiple day } \\
\text { bookings }\end{array}$ & Averages about two nights & $\begin{array}{l}5 \text { - } 7 \text {-day trips are } \\
\text { most popular }\end{array}$ & $\begin{array}{l}\text { Multiple flight sectors are } \\
\text { possible }\end{array}$ & $\begin{array}{l}\text { Multiple days are } \\
\text { possible }\end{array}$ \\
\hline Deposit & By credit card upon booking & $\begin{array}{l}\text { Full payment } 70 \text { days } \\
\text { before departure }\end{array}$ & $\begin{array}{l}\text { Full payment for non- } \\
\text { refundable discount tickets }\end{array}$ & None \\
\hline No-show rate & Averages 5\% & Averages less than $1 \%$ & Averages $8 \%$ & $20 \%-25 \%$ \\
\hline $\begin{array}{l}\text { Late cancellation and } \\
\text { no-show penalty }\end{array}$ & $\begin{array}{l}\text { Equal to the first night's stay, } \\
\text { plus taxes }\end{array}$ & Equal to the entire trip & $\begin{array}{l}\text { Equal to the full fare in the } \\
\text { case of non-refundable tickets }\end{array}$ & None \\
\hline Holdovers & Averages 6\% & None & None & Considerable \\
\hline $\begin{array}{l}\text { Early departure } \\
\text { penalty }\end{array}$ & $\begin{array}{l}\text { Between US } \$ 30 \text { and US\$75, } \\
\text { but not common }\end{array}$ & $\begin{array}{l}\text { Partial refund } \\
\text { provided }\end{array}$ & Non-refundable & None \\
\hline Walk-ins & $\begin{array}{l}\text { Averages about seven rooms } \\
\text { per day }\end{array}$ & None & Very significant at airport & $\begin{array}{l}\text { Very significant } \\
\text { especially at airport }\end{array}$ \\
\hline Overbooking & $\begin{array}{l}\text { For cancellations, no shows, } \\
\text { and early departures }\end{array}$ & For cancellations only & $\begin{array}{l}\text { For cancellations and no } \\
\text { shows }\end{array}$ & $\begin{array}{l}\text { For cancellations, no } \\
\text { shows, and early returns }\end{array}$ \\
\hline Upgrades & Common & Very common & Common & Very common \\
\hline $\begin{array}{l}\text { Walks or denied } \\
\text { boarding }\end{array}$ & Averages 10 nights a year & Very rare & $\begin{array}{l}\text { About eight per } 10,000 \\
\text { enplaned }\end{array}$ & Common \\
\hline Group bookings & Averages $42 \%$ & Averages below $40 \%$ & Possible for tour groups & Rare \\
\hline Attrition clauses & Common & Rare & None & None \\
\hline Attrition penalties & Based on agreed room nights & Rare & None & Not applicable \\
\hline
\end{tabular}


Note that cruise lines, which require full payment about 60 days before departure, suffer the smallest percentage of cancellations and no shows (reservations followed by payment are known to be very sticky in that they are normally not cancelled), and concomitantly offer the most generous denied boarding compensation. Car rental agencies, on the other hand, do not require deposits or credit card numbers (except during peak periods in some high-density locations), and therefore experience very high no-show rates, requiring heavy overbooking. They have not developed any customary compensation plans for walks. And it was shown a long time ago [18] that the hotels generally outperform the airlines in lowering the late cancellation and no-show rates. Whereas the average no-show rate for hotel is about $5 \%$, the corresponding figure for the airlines is about $8 \%$.

\section{Recommendations and Conclusions}

Our review of the literature, survey results, comments by the room managers interviewed, and our own insights allow us to make the following recommendations for the hotel industry. First, in 1998, the hotel industry incurred an estimated US $\$ 13.5$ million in charge-backs for no shows, because $80 \%$ of the challenges were settled in favor of guests [19]. Note that, in spite of a 5\% no-show rate, the no-show penalties collected represent only $0.2 \%$ of industry revenue [10]. Thus, upon making a reservation, a guest should be told of the cancellation deadline and no-show penalty. Also, when accepting reservations, hotels should get the cardholder's address (as advised by MasterCard) and telephone number (as advised by Visa) as proof that the reservations were indeed made, when guests claim that there were none, since there is no other way that the information could have been collected. Some hotels are now even sending credit card authorization forms to guests for their signatures to confirm reservations. And if a guest cancels, a cancellation number should be given. This is because, should a billing dispute arise, if the guest cannot provide a cancellation number, then the credit card company will rule in the hotel's favor.

Second when a guest checks in, the penalty for early departure should be spelled out to avoid future misunderstandings. Many hotels have been asking guests to initial a document that specifies the departure date. But one must be flexible, because early departure penalties can easily be turned into an ugly service issue. Thus if a guest complains about paying for something that is not widely known (only one-quarter of our hotels interviewed impose this penalty), most room managers will drop the matter, possibly perpetuating the problem. Also, the penalties should be waived for family emergencies. Meeting planners are in favor of early departure penalties, because they reduce the number of early departures of conventioneers and attrition penalties, and make it easier to plan for departure banquets. In fact, some meeting planners have started imposing their own no-show and early departure penalties on their members. Pre-announced early departure penalties also compel guests, upon checking in, to announce 
their intention to leave earlier than previously booked, thus allowing other guests to gain access to rooms that would have been booked but left empty.

Third, walks damage goodwill, therefore planning for walks should start as early as 12 noon, after the checkout time and after the number of holdovers and early departures are known. Also, whenever a guest is walked, it is best that everything be done to placate the displaced guest to ensure repeat business and prevent bad publicity through word of mouth. One hotel provides a free night on one future stay to regular customers, others provide a free upgrade when the guest is brought back to the first hotel, others give bonus frequent-stayer award points, while another sends flowers to the room, all meant to recapture lost goodwill. Several hotels mentioned that it is easier to walk leisure guests who appreciate the free night(s) more than business travelers whose corporations pick up the bill. In all cases, it is best to ask for volunteers to walk, just as the airlines are doing by way of open auctions, and the cruise lines are doing through silent ones. When pressed for an explanation as to why the guest is being walked, it would be better and equally valid to attribute the oversale to holdovers (guests' fault) than to overbooking (hotel's fault). This may appear as misrepresentation, but is factually true, because on almost all days, some guests will not leave as scheduled. And if the situation gets ugly, do what the airlines do-walk someone in uniform. You are less likely to get an argument from this person, because people in identifiable uniforms seldom make a scene-something the airlines already know and are surreptitiously implementing.

Fourth, meeting planners can minimize or reduce attrition damages and wastage by educating attendees, imposing penalties on those who cancel late, no show, or leave early, monitoring reservation trends, and by negotiating reductions in blocks to conform to historical trends. They should also ensure that group rates are sufficiently low to discourage attendees from booking outside the block. Otherwise, they will pay for it in lost complimentary rooms and increased attrition penalties.

Fifth, another issue that has emerged is conventioneers booking around the system, for example, through the Internet. In such cases, convention planners have asked hotels to provide them with the entire guest list, so that missing conventioneers can be identified and credited against attrition penalties. One hotel we interviewed routinely declines this type of request for privacy reasons, and instead asks convention planners to submit a list of all attendees to check for conventioneers that have not been credited toward the room block. We think that this is a good practice. But if the meeting planner is very insistent, as a compromise, the hotel should consider sending a list of only the last names of the hotel's guests, to prevent full identification, and to protect their privacy. If the meeting planner recognizes a last name, he or she can then submit the first name to the hotel for verification to see if it belongs to the room block.

Sixth, a related issue is a hotel assessing the first night's room rate plus taxes for a conventioneer's no show, collecting damages from the convention planners 
by way of attrition clauses, and then reselling the empty room, amounting to triple dipping, because the room is sold three times. Thus this makes it more compelling for convention planners to insist that no-show penalties should be credited toward the room block.

Seventh, attrition clauses should be enforced firmly but judiciously. These "pick up or pay clauses" have been described as the most contentious issue in the industry. The overall impression we got from the room managers we interviewed is that they would do everything possible to avoid arbitration or litigation to enforce no-show or early departure penalties on groups. One hotel insists that both parties must attempt to resolve the outstanding issues for a minimum period of 31 days before resorting to arbitration or litigation. Many hotels will accept liquidated damages representing a portion of the total penalty. Others will waive the penalties in return for a group booking during off-peak periods in the future. And all of them encourage convention planners to inform them of anticipated shortcomings in expected attendance, so they can resell into these block bookings to minimize the attrition damage. If the shortfall is minimal, everything is forgiven to preserve goodwill and ensure future business, especially with repeat customers such as airlines and tour agencies. Note that many conventions are organized by professional meeting planners, who repeatedly steer convention business to those hotels that have served them well in the past. But we recommend that for non-regular groups (regular groups would include airline crew, travel agency blocks, etc.), hotels should insist on a deposit equal to one night's stay plus taxes to ensure that the group shows up, and minimize collection problems when they do not. One hotel that we interviewed is already doing this.

We conclude by making two final observations. First, throughout the paper, we have talked about non-performance penalties. We used the term "penalty" in its full generic sense (widely found in the literature), meaning any sort of financial loss associated with non-performance. However, in all the instances we have explored, no-show penalties, early departure penalties, and attrition penalties, there is some element of liquidated damages or "walk away" amount. For instance, if you do not pick up your group room block, you agree to pay a predetermined amount that is meant to compensate the hotel for your non-performance. But a general principle of contract law is that liquidated damages must not be punitive in nature. Thus hoteliers are cautioned not to use the word "penalty" in any of their formal communications, otherwise the courts will not enforce the contract. Instead, hotels should use the word "charge" or "fee," but never "penalty."

Second, almost all the room managers that we interviewed are very experienced professionals who have worked at several positions within the hospitality industry, and most have worked their way through the ranks. When we asked some of them whether computers could make all the decisions on overbooking and enforcement of non-performance penalties, they all indicated that there are too many things that cannot be anticipated or programmed. We agree with this 
assessment. Even when guided by proprietary company-wide room management computer programs, all the room managers were obliged to exercise good judgment based on accumulated experience to deal with assorted issues on a caseby-case basis, and to over-ride and intervene when appropriate. We thank them for the time they took off from their very busy schedules to speak to us on up-to-date issues and practices in the hospitality industry.

\section{Conflicts of Interest}

The author declares no conflicts of interest.

\section{References}

[1] Gould, R.E., Ramsey, T.J. and Sherry, J.E.H. (1980) The Hotelkeeper's Contract and the International Traveler. Cornell Hotel and Restaurant Administration Quarterly, 20, 67-74. https://doi.org/10.1177/001088048002000413

[2] Toh, R.S. and Dekay, F. (2002) Hotel Room-Inventory Management: An Overbooking Model. The Cornell Hotel and Restaurant Administration Quarterly, 43, 79-90. https://doi.org/10.1016/S0010-8804(02)80044-1

[3] Goldstein, M. (1997) Some Car Rental Companies Are Testing Guaranteed Reservations Program to Penalize No-Shows. Travel Agent, 287, 49.

[4] Ladany, S.P. (1996) Optimal Market Segmentation of Hotel Rooms-The Non-Linear Case. Omega, 24, 29-36. https://doi.org/10.1016/0305-0483(95)00045-3

[5] Weatherford, L.R. and Bodily, S.E. (1992) A Taxonomy and Research Overview of Perishable-Asset Revenue Management: Yield Management, Overbooking, and Pricing. Operations Research, 40, 831-844. https://doi.org/10.1287/opre.40.5.831

[6] Rothstein, M. (1974) Hotel Overbooking as a Markovian Sequential Decision Process. Decision Science, 5, 389-404. https://doi.org/10.1111/j.1540-5915.1974.tb00624.x

[7] Bitran, G.R. and Mondschein, S.V. (1995) An Application of Yield Management to the Hotel Industry Considering Multiple-Day Stays. Operations Research, 43, 427443. https://doi.org/10.1287/opre.43.3.427

[8] Hadjinicola, G.C. and Payani, C. (1997) The Overbooking Problem in Hotels with Multiple Tour Operators. International Journal of Operations \& Product Management, 17, 874-885. https://doi.org/10.1108/01443579710171208

[9] Badinelli, R.D. (1998) An Optimal, Dynamic Policy for Hotel Yield Management. European Journal of Operations Research, 12, 476-503. https://doi.org/10.1016/S0377-2217(99)00046-6

[10] De Lollis, B. (2002, August 27) Hotels Get Less Hospitable about Late Cancellations. USA Today, 6B.

[11] Yesawich, P. (1977) Know Your Prime Prospects: Marketing Research for the Lodging Industry. Cornell Hotel and Restaurant Administration Quarterly, 17, 11-16. https://doi.org/10.1177/001088047701700403

[12] Weatherford, L.R. (1995) Length of Stay Heuristics: Do They Make a Difference? Cornell Hotel and Restaurant Administration Quarterly, 36, 70-79. https://doi.org/10.1177/001088049503600620

[13] Barth, S. (2001) Solving the No-Show Dilemma. Lodging Hospitality, 57, 9.

[14] Cassedy, K. (1998) Negotiating Rates in a Hotel Sellers' Market. Association Management, 50, 61-63, 68 . 
[15] Howe, J.T. (2000) Are Some Planners Being Charged Twice When They Don't Meet Their Room Guarantee? Meetings and Conventions, 35, 40.

[16] Howe, J.T. (2001) Sharing the Blame. Meetings and Conventions, 36, 30.

[17] Ghitelman, D. (1998) As Hotels Pile on the Penalties, Planners Fight back. Meetings and Conventions, 33, 48-50.

[18] Toh, R.S. (1986) Coping with No-Shows, Late Cancellations, and Oversales: American Hotels Out-Do the Airlines. International Journal of Hospitality Management, 5, 121-125. https://doi.org/10.1016/0278-4319(86)90004-6

[19] Seal, K. (1999) Hotels, Credit-Card Companies Debate Discretionary Billing. Hotel and Motel Management, 214, 1-13b. 